\title{
Sexual Issues in Treating Trauma Survivors
}

\author{
Aline P. Zoldbrod
}

Published online: 17 December 2014

(C) The Author(s) 2014. This article is published with open access at Springerlink.com

\begin{abstract}
The effect of interpersonal trauma on sexuality can be profound. The field of sexual trauma is complex empirically and clinically, with contradictory theories and conflicting data. Research definitions and treatment protocols for child sexual abuse are very imprecise. There are no firm, empirically proven guidelines for treating men and women who have been sexually abused as children or adolescents. Overt sexual abuse (OSA) in children and adolescents is defined here as molestation, rape, or incest. Research has shown that OSA may, but does not necessarily, lead to sexual dysfunction in adulthood. The effects of OSA are worsened by concurrent types of family of origin abuse, such as emotional abuse or physical abuse. One factor that seems related to the varying impact of OSA on adult sexuality is the patients' family of origin experience with nonsexual Milestones of Sexual Development. Without positive experiences with touch, trust and empathy, the ability to relax and be soothed, and power, the effects of OSA are potentiated and complicated. Sexuality is embodied, so experiences with touch are particularly important when working with OSA. A three-color Body Map technique which assesses stored associations to touch is provided. The concept of developmental sexual trauma (DST) is introduced as a way to label traumagenic family events which potentiate OSA or negatively effect sex but which are not explicitly
\end{abstract}

This article is part of the Topical Collection on Integrating the Psychosocial

A. P. Zoldbrod $(\bowtie)$

Lexington, MA, USA

e-mail: dralinez@sexsmart.com

URL: http://www.sexsmart.com

A. P. Zoldbrod

Affiliate faculty, University of Michigan Sexual Health Certificate Program, Ann Arbor, MI, USA sexual in origin. Strategies to assess and treat OSA are reviewed. Body Maps are recommended to assess and treat sexual trauma.

Keywords Developmental sexual trauma (DST) · Family of origin · Milestones of Sexual Development · Body Map . Touch · Trust · Overt sexual abuse $\cdot$ Sexual compulsivity . Family violence $\cdot$ Emotional neglect

\section{Introduction}

"It's really hard to be in my body in the presence of other people and feel safe."-57-year-old woman, married, presenting for sex therapy, and survivor of emotional, physical, and sexual abuse.

Sexual trauma, in all its forms, is common in the USA and, indeed the world [1], with negative implications for the optimal sexual health, pleasure, and functioning of male and female survivors. Being able to have intimate, engaged sexual encounters is critical to having vital romantic relationships [2,3]. The primary focus of this paper is overt sexual abuse (OSA): child and adolescent molestation, rape, and incest. However, assessing and treating sexual trauma is complicated. Researchers and clinicians consistently have pointed out the negative effect of all forms of childhood maltreatment on adult sexual functioning [4-6]. As research continues, it is clear that other kinds of abuse in the family, including neglect, physical abuse, emotional abuse, and witnessing physical violence, are quite common [7•]. They potentiate the psychological and sexual effects of OSA. These other kinds of abuse can be considered developmental sexual trauma (DST). They damage adult sexuality by affecting the patients' feelings, associations, and implicit memories about touch, trust, safety, power, and gender. 


\section{Overt Sexual Abuse}

Overt sexual abuse (OSA) is the intentional arranged participation of the child in sexual activities which are developmentally inappropriate and for which the child cannot give informed consent and, in adolescents, rape.

Accurate prevalence statistics come from large studies collected by California HMOs. Dube et al. [8] published a 2005 study of 17,337 adult HMO members using a control group as well as controlling for exposure to other kind of childhood trauma. They found contact child sexual abuse reported by $16 \%$ of males and $25 \%$ of females. OSA statistics, research, and thus clinical understanding are hampered by differing definitions of sexual contact, huge variations in the intensity, type, and longevity of the abuse, vast differences in the family environments the children come from, inconsistent definitions of the end of childhood, lack of control groups, and questions about the veracity of retrospective recall by adults $[9,10]$. Probably because of these definitional problems, one meta-analysis concluded that the harm caused by child sexual abuse was not necessarily intense or pervasive [11].

Incest is OSA perpetrated by a family member. Children's symptoms are more severe when sexual abuse is by parent figures [12], when it involves penetrative sex, when it is accompanied by aggression, when there are several abusers, and/or when it continues over months or years [5, 13, 14]. Finkelhor [15] writes brilliantly about the betrayal the child experiences and about the child's sexualization, powerlessness, stigmatization, and change in worldview. Maternal support has been shown to be the most crucial factor in children's recovery from child sexual abuse [16, 17].

In adults, OSA has been correlated with higher levels of depression, guilt, shame, and self blame, all of which are likely to affect comfort with sexuality. In a carefully constructed study of adult survivors of OSA, male and female OSA survivors had significant social and relationship problems and suicidality [8], and women had lowered self-esteem and decreased life satisfaction [18].

Maltz [19] described the most common sexual symptoms stemming from sexual abuse as follows:

Avoiding, fearing, or lacking interest in sex; approaching sex as an obligation; experiencing negative feelings such as anger, disgust, or guilt with touch; having difficulty becoming aroused or feeling sensation; feeling emotionally distant or not present during sex; experiencing intrusive or disturbing sexual thoughts and images; engaging in compulsive or inappropriate sexual behaviors; vaginal pain or orgasmic difficulties in women; and erectile, ejaculatory, or orgasmic difficulties in men.

Sexual abuse research has been focused primarily on females, children, and adults. Less attention has been focused on adolescents and men. Some excellent research exists on the sexual sequellae of female survivors of OSA and corroborates Maltz. However, it should be noted that researchers examining the association of OSA with women's sexual functioning describe conflicting results, with some studies finding very modest effects [20]. Several studies have found that OSA histories in women are more associated with problems with sexual satisfaction rather than sexual function per se $[9,10$, 21].

In studies, OSA survivors were found to have distortions in sexuality [22, 23] including heightened sexual activity and permissive attitudes [24, 25] (e.g., excessive masturbation and an overactive sexual fantasy life); sexual risk-taking behaviors [26]; early pregnancy [27]; compulsive sexual behaviors [28, 29], e.g., prostitution [30]; sexual avoidance [31]; anxiety and fear of being sexual [32]; changed self schemas and negative affect during sexual arousal $[33,34]$; and sexual dysfunction [9, 35]. Finally, women OSA survivors frequently present with somatic chronic pelvic pain [36-38].

There are far fewer studies of the sexual sequellae of OSA in men than in women. The research which exists documents a significant negative effect on sexuality, with males more likely to act out sexually and to engage in other self-destructive behavior [20]. Significant correlations between OSA and sexual dysfunction are found $[39,40]$. In a national probability sample of 1749 women and 1410 men aged 18 to 59 years, Laumann, Paik, and Rosen [34] found that for male survivors, OSA had significant sexual effects. For men who were touched sexually before puberty, all categories of sexual dysfunction were more common than in men who had not been sexually abused. Forceful penetrative sex is associated with high-risk sexual behaviors [41]. One large study of 1002 male college students found that male victims are much more likely to experience adult sexual assault than nonvictims. [42]. Male socialization and shame prevent men from acknowledging OSA, hindering healing [43•]. It appears that some adolescent males eroticize OSA experiences and deny them as abusive. Experiencing OSA may be one factor leading to sexual compulsivity in men [44-46].

The Importance of the Family in which the Sexual Trauma Occurs: OSA, the Milestones of Sexual Development and Developmental Sexual Trauma

The family environment in which the OSA occurs is a critical determinant of how well survivors fare [7•, 47]. Powerful, recent research indicates that most survivors of serious OSA come from dysfunctional families where usually there are other adverse childhood experiences_-physical abuse, neglect, emotional abuse, family violence, or alcohol or drug abuse [48]. Research consistently finds that survivors of OSA fare worse with each type of adverse childhood experience [48-50]. 
Nonsexual family of origin abuse, such as emotional abuse, causes negative sexual sequellae on its own, separate from OSA [21]. On the other hand, the presence of powerful, positive Milestones of Sexual Development, such as good family experiences with touch, trust, empathy, safety, relaxation, and power, can offset the trauma of some experiences with OSA. The absence of these good family experiences is DST, which intensifies the trauma of OSA.

Good Milestone experiences "link feelings of being loved and feeling 'good enough' with other developmentally and sexually crucial abilities and associations, for instance, with:(1) embodied feelings of pleasure, including (appropriate) familiarity with the sights, touches, tastes, and smells of bodily intimacy; (2) the ability to tolerate feelings, one's own and others'; (3) emotional closeness to another; (4) relaxation, trust, safety, and energy flow; (5) the expression of feelings; and (6) ultimately, with the free expression of sexuality [51]" and sexual satisfaction.

\section{Good and Bad Associations to Touch, OSA, and Trauma}

Good associations to touch are a crucial Milestone of Sexual Development that is subverted by OSA. Untraumatized children crave touch, sensation, and close physical intimacy [52]. Researchers [53 p 124] spoke with 31 children aged 8 to 9 years, along with their parents about cuddling and being in love. "Almost all of them regarded cuddling as something positive, either because of the bodily sensations or because of the feeling of safety it gives them ( $p$ 123)." The childrens' associations to cuddling were safe, nice, soft, cheerful, fun, kind, and comforting. They reported having many areas in their body in which touch felt pleasant and several areas (none of them erogenous) where touch felt exciting. More than half of them deemed themselves to have been in love. Their associations to being in love were positive and made reference to pleasant physical sensations.

When associations to touch are damaged in childhood, patients' ability to experience sexual pleasure is seriously impacted. In a study of 1000 French men and women, touch was the most important of all the senses for sexual pleasure for both men and women, and foreplay was "important, very important, or essential" for $89.1 \%$ of subjects [54]. Research and clinical literature indicates, at least for non-abused women, that receiving pleasurable touch that does not lead to intercourse and sufficient pleasurable touch prior to intercourse leads to good sexual function $[55,56]$. Good associations to touch are subverted by OSA, DST, and family violence. Traumatic experiences with touch are stored in the body as implicit memories and unpleasant sensations, split off from conscious awareness $[57 \bullet \bullet, 58,59 \bullet]$. Experiencing family physical violence toward oneself or watching violence between parents is common among families where there is OSA, potentiates OSA, and has its own sexual sequellae.

\section{Body Maps in Evaluating and Treating Trauma and Stored Negative Sensation}

In evaluating and treating sexual trauma, it is useful to have patients draw three-color Body Maps, which assess stored implicit and conscious trauma [4] (see Fig. 1 and Table 1). I devised this clinical tool in the 1990's. Patients are asked to draw an outline of the front and the back of their body, and thinking of being touched by someone they love, to color in the map. The color code is the same as a traffic light: green means go; yellow means caution or it depends; red means no. Most survivors of OSA will not be surprised to find their genitals, buttocks, anus, or their mouths red, but they may well be surprised to see how the bad feelings have spread to the rest of their body (often indicating concurrent DST). Some OSA patients have dissociated the trauma memories, but the Body Maps alert the professional to the occurrence of trauma. Survivors of DST may well be bewildered by what their Body Maps evidence, since they do not count what happened to them as abuse. Memories of gender microaggressions [60] from strangers and peers also show up on Body Maps.

\section{Treating OSA}

Because different instances of OSA vary so much, there is no specific "sexual abuse syndrome" among survivors, nor has any specific treatment model has been proven efficacious $[61 \bullet \cdot$. When a patient reveals a history of sexual abuse, the clinician should not presume to know what its effects are.

It is critical to screen for all kinds of family of origin traumatic experiences, including DST. Use of a screening tool such as the Childhood Trauma Questionnaire [62] is recommended. Most screening tools do not ask about exposure to pornography, and including this variable is worthwhile.

The Body Map exercise described herein indicates whether the patient has any nonverbal, implicit, feared sensations or memories of trauma. If there is very little green on the Body Map, the therapist must proceed cautiously. The data evidenced on the Body Map may not be consciously known to the patient. Before processing the Body Map, it is critical that a therapeutic alliance be established and that patients have developed the internal resources to tolerate the sensations and the memories of the trauma [63-65]. The clinician should assess for suicidality and dissociative phenomena. If the patient clearly has complex trauma, a dissociative disorder, or is at risk for suicide, a referral out may be appropriate.

Newer research reviewed by Rellini [61・•] shows that interventions that use mindfulness contribute to healing 
Fig. 1 Body Maps

Body Maps Illustrating Stored Trauma

Please touch $\square$ It depends, maybe $\square$ Do not touch!

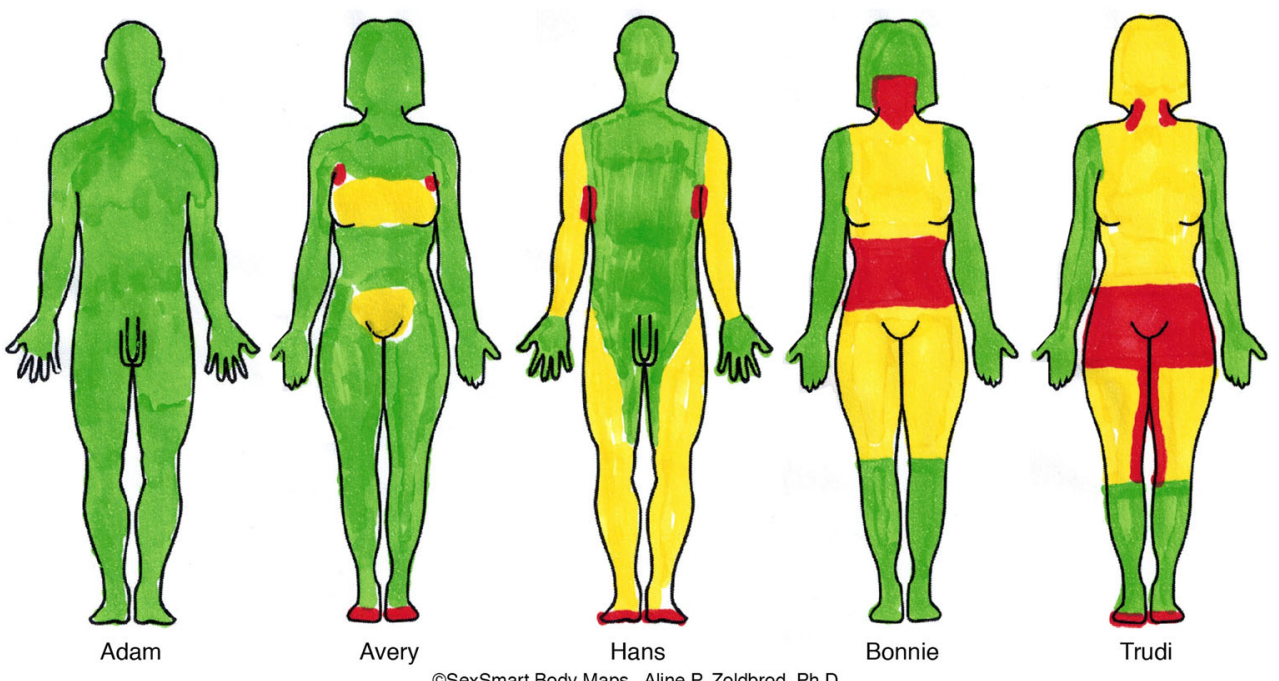

(c) SexSmart Body Maps Aline P. Zoldbrod, Ph.D.
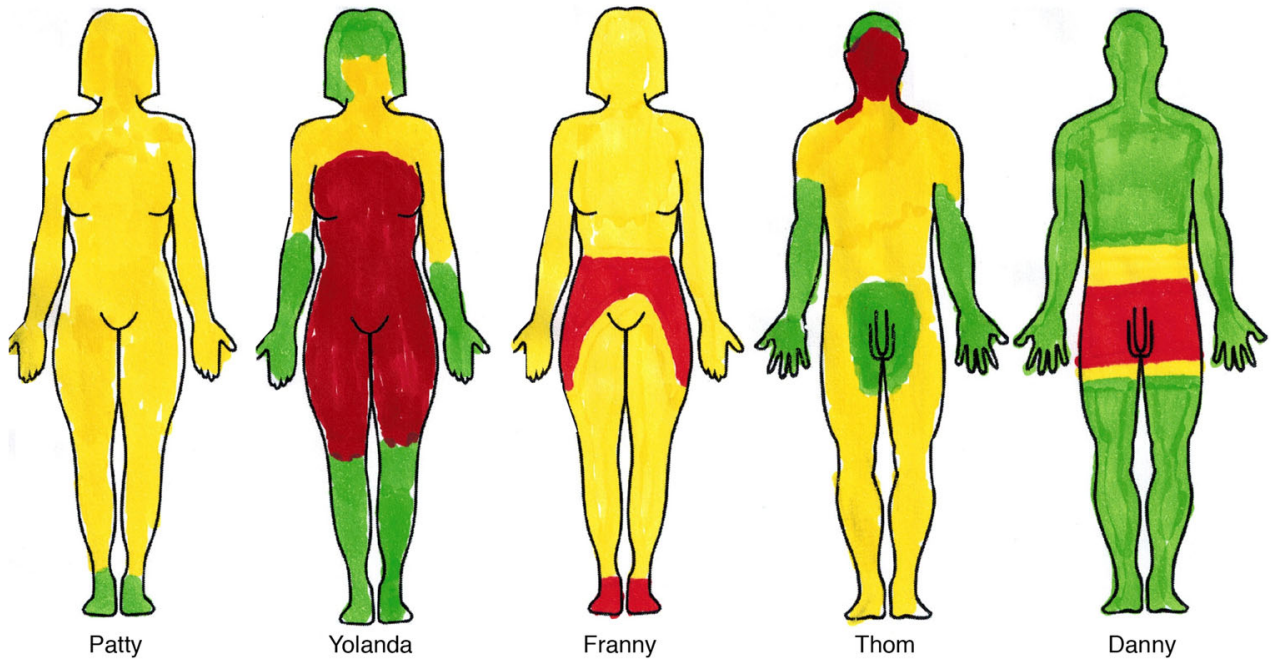

OSA [66]. This is congruent with current trauma research, which finds that mindfulness aids emotional regulation and can lead to changes in brain regions related to body awareness and fear $[57 \cdot \bullet]$.

Maltz [19, 67, 68] suggests that a first step in healing is to help the survivor to connect their current sexual problems with their past sexual trauma. Maltz stresses the importance of the survivor gaining skills in assertiveness and self awareness. If the survivor is in a committed relationship, their partner can be an active participant in the healing process. Establishing choice, trust, respect, safety, and equality in the relationship is an important precondition to couples work going forward. Other OSA literature remains relevant and useful [69-71], employing case studies, carefully staged treatment and an emphasis on safety, and maintaining the survivor's sense of agency and power in the present.

Because childhood sexual abuse has been correlated with higher levels of depression, guilt, shame, and self blame, all of which are likely to affect comfort with sexuality, researchers have looked at altering self schemas of survivors of OSA [35]. There is a huge role for psychoeducation, support groups, [72••], and group therapy in addressing self blame and shame. When the sexual abuse was inflicted by an esteemed trusted adult, it may have been hard for the survivor to see the perpetrator through adult eyes, making it difficult for them not to blame themselves. In a group, each participant can see that the other group member's perpetrator was at fault, identify with the other person, and let go of their guilt, self blame and shame. 
Table 1 How To Use Body Map to Screen for Hidden and Stored Trauma @Aline P. Zoldbrod

Color key: green $=$ please touch; yellow $=$ it depends; red $=$ no!

\begin{tabular}{ll}
\hline Possible trauma condition & Typical color scheme \\
\hline $\begin{array}{l}\text { Typical man with } \\
\text { no trauma }\end{array}$ & $\begin{array}{c}\text { Almost entirely green, perhaps } \\
\text { small areas of red and yellow }\end{array}$ \\
$\begin{array}{l}\text { Typical woman with } \\
\text { no trauma }\end{array}$ & $\begin{array}{l}\text { Almost all green. } \\
\text { Breasts, pudendum, and anus } \\
\text { typically yellow } \\
\text { Note: women often color primary } \\
\text { erogenous zones yellow because } \\
\text { they prefer to become aroused with } \\
\text { whole body touches before having primary } \\
\text { erogenous zones touched. } \\
\text { Small amounts of red and yellow may } \\
\text { be present. }\end{array}$
\end{tabular}

\section{No trauma. But family sex-negative. \\ Green and some yellow. \\ Perhaps small red areas}

Family did not touch.
Issues to treat

explore/ask

- Explore any yellow or red areas; may indicate injury, illness, uncomfortable feelings about body parts.

- Explore as above.

- Be sure to decode any red or yellow areas - may indicate having been touched in an unpleasant way, pain or injury, or body image issues.
Example

(see figure by name)

Adam

Avery

- Hans actually has become much more comfortable with touch as an adult. In his drawing of himself as an adolescent, his genitals were yellow. His wife taught him about the pleasures of being touched. His red areas are where he is ticklish.

-Where you see large areas of red, or large areas of yellow, be mindful, cautious.

- Do not open up trauma memories before you have worked to give patient inner resources to handle upsetting sensations.

- It is not unusual to see red on womens' abdomens without physical abuse there. May mark dislike of belly fat.

- Bonnie was treated very harshly and her mother scratched her face on several occasions.

- Patty was hit occasionally, and received constant emotional and verbal abuse.

- Frannie had physical and emotional abuse and physical neglect.

- Thom was constantly emotionally abused and hit on face and shoulders.

- Danny came from a home with alcoholism and physical violence, but his mother was loving and affectionate. He feels insecure about his weight and his penis size. He has low desire and avoids sex.

- The patient bears witness to violence done Trudi to the other family member, often by holding trauma in the same body area where other person was assaulted.

- Trudi's mother was beaten by father repeatedly throughout Trudi's childhood. Mother stayed in relationship far too long.

- Note that genitals are red even without OSA. Trudi has profound ambivalence about being a sexual woman in relationship with a man. She does not want to identify with the gender of the victim of violence, her mother.
Bonnie

Franny

Patty

Thom

Danny 
Table 1 (continued)

Color key: green = please touch; yellow $=$ it depends; red = no!

\begin{tabular}{|c|c|c|c|}
\hline Possible trauma condition & Typical color scheme & $\begin{array}{l}\text { Issues to treat } \\
\text { explore/ask }\end{array}$ & $\begin{array}{l}\text { Example } \\
\text { (see figure by name) }\end{array}$ \\
\hline OSA and DST & Red on genitals from OSA. & $\begin{array}{l}\text { - Yolanda had intrafamilial sexual abuse that } \\
\text { continued for a long time, as well as physical } \\
\text { and emotional abuse. }\end{array}$ & Yolanda \\
\hline $\begin{array}{l}\text { Other possible explanation: } \\
\text { Gender microaggression } \\
\text { outside of family }\end{array}$ & $\begin{array}{l}\text { Mixed color scheme not accounted } \\
\text { for by any intrafamilial trauma }\end{array}$ & $\begin{array}{l}\text { - Person receives demeaning sexual, gender } \\
\text { or body-focused comments. } \\
\text { - Preadolescent girls whose breasts develop early } \\
\text { and adolescent girls with large breasts are } \\
\text { targets of hostile, sexual, objectifying comments. } \\
\text { - Boys targeted because of height or penis size. } \\
\text { - GBLT adolescents are targets of shaming, } \\
\text { hostile comments about height, gait, } \\
\text { gender-variant appearance. } \\
\text { - For all, resulting feelings of shame and } \\
\text { confusion are stored in body. }\end{array}$ & $\begin{array}{l}\text { No example } \\
\text { provided in Body } \\
\text { Map graphic }\end{array}$ \\
\hline
\end{tabular}

\section{Some Additional Thoughts on Treating OSA}

There is an important piece that is missing from the discussion on treating OSA. Sex is embodied. Enjoying sexuality is not a cognitive process. For some OSA patients, the ones who have very little green on their Body Maps, the body holds the terror $[57 \bullet \bullet, 58]$. From this perspective, avoiding sex, fearing arousal, and lack of desire make sense. If there was DST or other types of family trauma, with no positive associations to touch or trust, there may be layer upon layer of stored fear and multiple places in the body where sensation feels dangerous. This becomes evident through patients' three-color Body Maps.

Where untraumatized children like the ones described in Rademakers' research [53] can grow into adults who enjoy sex, hugging, and kissing, the OSA survivors we treat feel quite the opposite. Their associations, when asked to make a list of associations to touch, are [4]: "fear," "controlling," "out of control," "pain," "awkward," "numb," "tense/anxiety," "guilt," "startle response," "bad memories," "discomfort," "weird," or "danger."

If survivors of mild OSA with DST were neglected and never touched lovingly, feelings of vulnerability and the longing to be touched and loved may be too powerful to tolerate (as is their partner's longing to be cared for). These patients' associations to touch can be "what does this mean?, "is this proper?," "numb," or that "touch is "boring" and a "waste of time."

Patients with Body Maps without much green avoid sex because the fear of the sensations has been wired into their brains. They are phobic of their own sensations. Being sexual with a partner, not knowing where you might be touched or how you might be touched, is a vulnerable experience. Healing the patient's fear of being touched, of feeling out of control, of unleashing frightening sensations is often a critical task, and traditional cognitive therapy or sensate focus is unlikely to be therapeutic. In individual, trauma-informed therapy, the therapist can slow down her volume and rate of speech. The therapy focuses on mindfulness, attentiveness to the present, being in one's body, the expression of emotion, and the therapeutic use of language [59•]. The goal is to get the patient to be curious about what she is feeling, to not avoid emotions and sensations. The environment the therapist creates is one that causes mild to moderate stress. The goal is to expose the patient to some of the upsetting and forbidden emotions and sensations but in a safe and contained way, with the therapist at the patient's side, helping to construct a narrative about what went on, what the emotions were at the time, and the fact that the patient is now safe.

Some schools of therapy talk about reexperiencing trauma in dual consciousness. The emotions are felt in the body in the present, and they feel frightening and difficult to tolerate. But at the same time, the patient knows that it is old feelings that she is feeling right now. Though the emotions seem vivid and feel intolerable, they do not represent a current danger. So she learns the skill of tolerating and noticing what she feels without automatically acting on the fear. These ideas about how to reprocess trauma involve the ability to reconceptualize a memory based on developing maturity. It is a breakthrough when a female OSA survivor can relax, call up a feared memory, focus, feel the sensations, picture herself as the girl with the terrifying emotions in her body, and speak to her young self as her adult self compassionately and soothingly.

Under the intense terror of severe OSA, the part of the brain that processes in words shuts down $[57 \bullet \bullet, 73]$. Through trauma-informed therapy, finally, it is possible to create a new narrative that places the negative emotions and memories attached to the sensations in the past. Over time, the Body Maps are redrawn. As the sensations, emotions, and thoughts get integrated, the Body Maps 
show more green. At that point, couple sex therapy could be most helpful.

\section{Summary}

Sexual abuse of children and adolescents is a serious problem, with long-lasting consequences for some survivors. Each patient who experienced OSA must be evaluated as a case of one. Because of the huge variations in the definitions and types of OSAs, and differences in the kinds of families patients came from, it is possible that some patients had no ill effects from the trauma.

Evaluation for OSA is complicated and should include taking a complete trauma history, looking at the specifics and the severity of the sexual abuse that occurred, whether the patient had some concurrent good experiences in the Milestones of Sexual Development or had DST, whether or not the trauma was revealed to parents, and how the parents or guardians responded to the revelation. It is critically important to determine whether or not other adverse childhood experiences like experiencing or witnessing physical violence or suffering emotional abuse or neglect occurred in the family of origin, since we know that these events complicate and potentiate the damage of the OSA.

Research indicates that both male and female survivors of OSA have sexual problems stemming from the abuse. Compared to the research on females and children, the research on the effect of OSA on male survivors is relatively sparce. Male socialization and reluctance to label OSA as abuse is evident in the fact that male survivors are less likely to seek help from professionals and to act out instead. Mental health and medical professionals should not assume that male survivors will spontaneously reveal a history of OSA without being queried. Providers should take care not to minimize revelations of OSA by male survivors, since they may already feel stigmatized, confused, and ashamed at being victims.

Some patients with OSA had many other traumatic experiences and may present with complex trauma. Care should be taken not to elicit too much traumatic material until the therapeutic alliance is strong, and patients have the internal resources and the skills to regulate their affect and tolerate and process disturbing feelings, memories, and sensations in dual consciousness.

Research has not proven any specific treatments as effective in the treatment of OSA in either men or women; however, mindfulness techniques do show promise. The current clinical literature does a good job of outlining the issues and describing a thoughtful way to proceed with treatment. The Body Map exercise may be a helpful addition to evaluate the depth of the trauma, and in appropriate patients, can be useful to gauge progress throughout treatment.

\section{Compliance with Ethics Guidelines}

Conflict of Interest Aline Zoldbrod declares no conflicts of interest.

Human and Animal Rights and Informed Consent This article does not contain any studies with human or animal subjects performed by the author.

Open Access This article is distributed under the terms of the Creative Commons Attribution License which permits any use, distribution, and reproduction in any medium, provided the original author(s) and the source are credited.

\section{References}

Papers of particular interest, published recently, have been highlighted as:

- Of importance

-. Of major importance

1. Mackay J. The Penguin atlas of human sexual behavior; sexuality and sexual practice around the world. New York: Penguin; 2000.

2. Shaver P, Mikulincer M. A behavioral systems approach to romantic love relationships: attachment, caregiving and sex. In: Sternberg R, Weiss K, editors. The new psychology of love. New Haven: Ct. Yale University Press; 2006. p. 35-64.

3. McCarthy B, Bodnar L and Handal M. Integrating sex therapy and couple therapy pp 573-593 in Harvey J, Wenzel A and Sprecher S. (eds) The handbook of sexuality in close relationships. 2004

4. Zoldbrod A. SexSmart: how your childhood shaped your sexual life and what to do about it. Oakland: New Harbinger; 1998.

5. Schloredt KA, Heiman J. Perceptions of sexuality as related to sexual functioning and sexual risk in women with different types of childhood abuse histories. J Traumatic Stress. 2003;16:275-84.

6. Rellini AH. Psychological factors of sexual abuse on women's sexual functioning. In: Goldstein I et al., editors. Women's sexual function and dysfunction: study, diagnosis and treatment. London: Taylor and Francis Group; 2005. p. 98-104.

7. Ferlitti VJ, Anda RF, Nordenberg D, Williamson DF, Spitz AM, Edwards V, et al. Relationship of childhood abuse and household dysfunction to many of the leading causes of death in adults: The Adverse Childhood Experiences (ACE) Study. Am J Prev Med. 1998;14:245-58. Research keeps being done on this important data set. You can keep up on the ongoing data collection .Current articles are available through the CDC at www.cdc.gov/acel.

8. Dube S, Anda RS, Whitefield C, et al. Long term consequences of childhood sexual abuse by gender of victim. Am J Prev Med. 2005;28(5):430-8.

9. Rellini AH, Meston CM. Sexual desire and linguistic analysis: a comparison of sexually abused and non-abused women. Arch Sex Behav. 2007;36:67-77.

10. Leonard L, Follette V. Sexual functioning in women reporting a history of child sexual abuse: a review of the empirical literature and clinical implications. Annu Rev Sex Res. 2002;13:346-88.

11. Rind B, Tromovitch P, Bauserman R. A meta-analytic examination of assumed properties of child sexual abuse using college samples. Psychol Bull. 1998;124(1):22-53.

12. Harter $\mathrm{S}$, Alexander $\mathrm{P}, \mathrm{Neimeyer} \mathrm{R}$. Long term effects of incestuous child abuse in college women: social adjustment, social cognition, and family characteristics. J Consult Clin Psychol. 1988;56(1):5-8. 
13. Kendall-Tackett KA, Williams LM, Finkelhor D. Impact of sexual abuse on children: a review and synthesis of recent empirical studies. Psychol Bull. 1993;113:164-80.

14. Meston CM, Heiman JR, Trapnell PD. The relationship between early abuse and adult sexuality. J Sex Res. 1999;36:385-95.

15. Finkelhor D, Browne A. The traumatic impact of child sexual abuse: a conceptualization. Am J Orthopsychiatry. 1985;55:530-41.

16. Cohen JA, Mannarino AP. A treatment outcome study for sexually abused preschool children: initial findings. J Am Acad Child Adolesc Psychiatry. 1996;35:42-50.

17. Elliott A, Carnes C. Reactions of non-offending parents to the sexual abuse of their child. Child Maltreat. 2001;6(4):35-49.

18. Fergusson DM, McLeod G, Horwood. Childhood sexual abuse and adult developmental outcomes. Child Abuse Negl. 2013;39(9): 664-74.

19. Maltz W. The sexual healing journey: a guide for survivors of sexual abuse. 3rd ed. New York: William Morrow; 2013.

20. Loeb T, Williams J, Carmona J, et al. Child sexual abuse: associations with the sexual functioning of adolescents and adults. Annual Rev Sex Res. 2002;13:207-345.

21. Lutfey K, Link C, Litman H, et al. An examination of the association of abuse (physical, sexual or emotional) and female sexual dysfunction: FSD results from the Boston Area Community Health (BACH) study. Fertil Steril. 2008;90(4):957-64.

22. Browning CR, Laumann EO. Sexual contact between children and adults: a life course perspective. Am Sociol Rev. 1997;62:540-60.

23. Miller BC, Monson B, Norton M. The effects of forced sexual intercourse on white female adolescents. Child Abuse Negl. 1995;19:1289-301.

24. Noll J, Trickett P, Putnam F. A prospective investigation of the impact of childhood sexual abuse on the development of sexuality. J Cosulting Clin Psychol. 2003;71(3):575-86.

25. Wilson JE, Wilson KM. Amelioration of sexual fantasies to sexual abuse cues in an adult survivor of childhood sexual abuse: a case study. J Behav Ther Exp Psychiatry. 2008;39:417-23.

26. Brown LK, Lourie KJ, Zlotnick C, Cohn J. Impact of sexual abuse on the HIV-risk-related behavior of adolescents in intensive psychiatric treatment. Am J Psychiatr. 2000;157: 1413-5.

27. Fiscella K, Kitzman HJ, Cole RE, Sidora KJ, Olds D. Does child abuse predict adolescent pregnancy? Pediatrics. 1998;101:620-4.

28. Friedrich WN, Urquiza AJ, Beilke R. Behavior problems in sexually abused young children. J Pediatr Psychol. 1986;11:47-57.

29. McClellan J, McCurry C, Ronnai M, et al. Age of onset of sexual abuse: relationship to onset of sexually inappropriate behavior. $\mathrm{J}$ Am Acad Child Adolesc Psychiary. 1996;34:1375-83.

30. Cunningham RM, Stiffman AR, Dore P, Earls F. The association of physical and sexual abuse with HIV-risk behaviors in adolescence and young adulthood: implications for public health. Child Abuse Negl. 1994;8:233-45.

31. Staples J, Rellini AH, Roberts S. Avoiding experiences; sexual dysfunction in women with a sexual abuse history in childhood. Arch Sex Behav. 2012;41:341-50.

32. Beitchman J, Zucker K, Hood J, et al. A review of the long term effects of child sexual abuse. Child Abuse Negl. 1992;16(1):10118.

33. Meston C, Rellini A, Heiman J. Women's history of sexual abuse, their sexuality and sexual self schemas. J Consult Clin Psychol. 2006;74(2):229-36.

34. Laumann E, Paik M, Rosen R. Sexual dysfunction in the United States: Prevalence and Predictors. JAMA. 1999;281(6): 537-44.

35. Rellini AH, Meston M. Sexual self schemas, sexual dysfunction, and the sexual responses of women with a history of childhood sexual abuse. Arch Sex Behav. 2011;40:351-62.
36. Heim C, Ehlert U, Hanker J, Hellhammer DDH. Abuse-related posttraumatic stress disorder and alterations of the hypothalamicpituitary-adrenal axis in women with chronic pelvic pain. Psychosm Med. 1998;6:309-18.

37. Reiter RC, Shakerin LR, Gambone JC, Milburn AK. Correlation between sexual abuse and somatization in women with somatic and nonsomatic chronic pelvic pain. Am J Obstet. 1991;165(1):104-109.

38. Walker E, Katon W, Harrop-Griffiths J, et al. Relationship of chronic pelvic pain to psychiatric diagnoses and childhood sexual abuse. Am J Psychiatry. 1988;1988(145):75-80.

39. Hunt S, Kraus S. Exploring the relationship between erotic disruption during the latency period and the use of sexually explicit material, online sexual behaviors, and sexual dysfunctions in young adulthood. Sex Addict Compulsivity. 2009;16(1):79-100.

40. Najman J, Dunne M, Purdie D, et al. Sexual abuse in childhood and sexual dysfunction in adulthood: an Australian population based study. Arch Sex Behav. 2005;34(5):517-26.

41. Senn T, Carey M, Vanable $P$, et al. Characteristics of sexual abuse in childhood and adolescence influence sexual risk behavior in adulthood. Arch Sex Behav. 2006;36:637-45.

42. Aosved A, Long P, Voller E. Sexual revictimization and adjustment in college men. Psychol Men Masculinity V. 2011;12(3):285-96.

43. Artine T, McCallum E, Peterson Z. Men's acknowledgement of their sexual victimization experiences. Psychol Men Masculinity. 2014;15(3):313-23. The literature on men's experience with sexual victimization is very scarce. This valuable article has an excellent review of the literature.

44. Tedesco A, Bola J. A pilot study of the relationship between childhood sexual abuse and compulsive behaviors in adults. Sex Addict Compulsivity. 1997;4:147-57.

45. Blain L, Muench F, Morgenstern J, Parsons J. Exploring the role of child sex abuse and posttraumatic stress disorder symptoms in gay and bisexual men reporting compulsive sexual behavior. Child Abuse \& Neglect. 2012:36(5):413-22.

46. Schwartz M, Galperin L, Masters W. Dissociation and treatment of compulsive reenactment of trauma: sexual compulsivity. In: Hunter M, editor. Adult survivors of sexual abuse: treatment innovations. Thousand Oaks: Sage; 1995. p. 42-55.

47. Fassler I, Amodeo M, Griffin M, et al. Predicting long-term outcomes for women sexually abused in childhood: contributions of abuse severity versus family environment. Child Abuse Negl. 2004;29:269-84.

48. Finkelhor D, Ormrod D, Turner H. Poly-victimization. A neglected component in child victimization. Child Abuse Negl. 2007;31(1): $7-26$.

49. Chartier MJ, Walker JR, Naimark B. Separate and cumulative effects of adverse childhood experiences in predicting adult health and health care utilization. Child Abuse Negl. 2010;34(6):454-64.

50. Dong M, Anda R, Dube S, Giles W, Ferlitti V. The relationship of exposure to childhood sexual abuse to other forms of abuse, neglect and household dysfunction during childhood. Child Abuse Negl. 2003;27(6):625-39.

51. Zoldbrod A. Assessing Intrapsychic blocks to sexual pleasure using the milestones of sexual development model. Contemp Sex. 2003;37(11):7.

52. Friedrich W. Studies of sexuality of nonabused children. In: Bancroft J, editor. Sexual development in childhood. Bloomington: Indiana U Press; 2003:107-20.

53. Rademakers J, Laan M, Straver C. Body awareness and physical intimacy: an exploratory study. In: Bancroft J, editor. Sexual development in childhood. Bloomington: Indiana University Press; 2003. p. 121-5.

54. Colson M, Lemaire A, Pinton P. Sexual behaviors and mental perception, satisfaction and expectations of sex life in men and women in France. J Sex Med. 2006;3:121-31. 
55. McCabe M. Childhood, adolescent and current psychological factors associated with sexual dysfunction. Sex Marital Therapy. 1994;9(3):267-76.

56. Ogden G. Women who love sex. New York: Trumpeter; 2007.

$57 . \bullet$ van der Kolk B. The body keeps the score: brain, mind and body in the healing of trauma. New York: Viking; 2014. A tour de force by one of the world's most prominent and articulate traumatologists, this fascinating book will explain the most modern ways of understanding trauma. Up to date and meticulously documented and illustrated review of neuroscience and the social science literature. Multiple chapters describe techniques like EMDR, Psychomotor Therapy, neurofeedback, internal family systems, and how to use yoga and mindfulness to reprocess disturbing sensations. This book is excellent both for practitioners and for patients.

58. Ogden P and Minton K. Trauma and the body: A sensorimotor approach to psychotherapy. New 2008.

59. Cozzolino L. The neuroscience of psychotherapy: healing the social brain. Second ed. New York: Norton; 2010. How a trusting, safe and emotionally significant psychotherapy or sex therapy relationship, practiced in a trauma-informed way, can rewire the patient's brain and change their life.

60. Sue S. Microaggressions in everyday life. New York: Wiley; 2010.

61.• Rellini $\mathrm{H}$. The treatment of sexual dysfunctions in survivors of sexual abuse. In: Binik Y, Hall K, editors. Principles and practice of sex therapy. 5th ed. New York: Guilford; 2014. p. 375-98. Rellini's excellent, thorough 2014 review of the epidemiology and assessment and treatment research on adult survivors of OSA is up to date and meticulous.

62. Bernstein D, Fink L, Handelsman L, et al. Initial reliability and validity of a new retrospective measure of child abuse and neglect. Am J Psychiatr. 1994;151(8):1132-9.
63. Herman JL. Trauma and recovery. The aftermath of violence. New York: Basic books; 1992

64. Briere $\mathrm{J}$ et al. Treating adult survivors of severe childhood abuse and neglect: further development of an integrative model. In: Myers L, Berliner J, Briere C, editors. The APSAC handbook on child maltreatment. 2nd ed. Newbury Park: Sage; 2002. p. 175-202.

65. Korn D, Leeds A. Preliminary evidence of efficacy for EMDR resource development and installation in the stabilization phase of treatment of complex posttraumatic stress disorder. J Clin Psychol. 2002;58:1465-87.

66. Brotto L, Basson R, Luria M. A mindfulness-based group psychotherapy-educational intervention targeting sexual arousal disorder in women. J Sex Med. 2008;5:1646-59.

67. Maltz W. Treating the sexual intimacy concerns of sexual abuse survivors. Sex Relationsh Therapy. 2002;17(4):321-7.

68. Maltz W and Holman B. Incest and sexuality: a guide to understanding and healing. 1987.

69. Hunter M, editor. The sexually abused male: prevalence, impact and treatment, Vols 1 and 2: Lexington, Ma. Lexington: Books; 1990.

70. Lew M. Victims no longer: men recovering from incest and other child sexual abuse. New York: Nevraumont; 1988.

71. Westerlund E. Women's sexuality after childhood incest. New York: Norton; 1992.

72.• Fradkin H. Joining forces: empowering male survivors to thrive New York: Hay House; 2012. Fradkin is one of the founding board members of MaleSurvivororg, a critically important resource for male survivors of sexual abuse.

73. van der Kolk B, Fisler R. Dissociation and the fragmentary nature of traumatic memories: overview and exploratory study. J Trauma Stress. 1995;8(4):505-25. 